\title{
ESTUDOS SOBRE EXPRESSÕES NÃO-MANUAIS DA LIBRAS: CONSTATAÇÕES E PERSPECTIVAS
}

\author{
Diego Teixeira de Souza ${ }^{1}$
}

Cátia de Azevedo Fronza ${ }^{2}$

\section{Resumo}

O objetivo deste artigo é fornecer um panorama de estudos que buscam esclarecer e/ou desvendar as funções exercidas pelas expressões não-manuais da Libras. Para isso, criaram-se oito palavras-chave que possibilitaram o encontro de cinquenta e quatro trabalhos que investigaram direta ou indiretamente essa especificidade da língua. Os dados foram tabulados de acordo com o ano de publicação e tema desenvolvido, o que possibilitou vermos que as informações apresentadas pelos estudos são circulares e trazem poucas novidades, muitas vezes, apenas retomando as já existentes. Há necessidade de mais pesquisas voltadas às expressões não-manuais da Libras a fim de se saber mais sobre esse aspecto.

Palavras-chave: Libras. Expressões não-manuais. Fonologia.

\section{STUDIES ON NON-MANUAL EXPRESSIONS OF BRAZILIAN SIGN LANGUAGE: FINDINGS AND PERSPECTIVES}

\begin{abstract}
The purpose of this article is to provide an overview of studies that aim to clarify the functions exercised non-manual expressions. For that, eight keywords were created that enabled the meeting of fifty-four researches that investigated directly or indirectly this specificity of the language. The data were tabulated according to the year of publication and topic developed, which made it possible to see the information presented similar studies There is a need for more research on non-manual expressions of Libras in order to learn more about this aspect.

Keywords: Libras. Non-manual expressions. Phonology.
\end{abstract}

\section{INTRODUÇÃO}

As investigações atuais (QUADROS, 2019; XAVIER, 2019) que possuem como objeto de estudo as línguas de sinais evidenciam que essas línguas apresentam especificidades assim como as línguas orais, como estruturação de orações, ordem das sentenças, concordâncias verbal e nominal.

\footnotetext{
${ }^{1}$ Universidade Federal do Rio Grande do Sul (UFRGS), Porto Alegre - Rio Grande do Sul - Brasil. Doutorando em Letras pela Universidade Federal do Rio Grande do Sul (UFRGS). É professor do Curso de Pedagogia, da Faculdade do Centro Educacional Santa Isabel (FACESI). ORCID <http://orcid.org/0000-0001-9530-8216>. Email: diegotsouza@uol.com.br.

${ }^{2}$ Universidade do Vale do Rio dos Sinos (Unisinos), São Leopoldo - Rio Grande do Sul - Brasil. É Docente do Curso de Letras e do Programa de Pós-Graduação em Linguística Aplicada, da Universidade do Vale do Rio dos Sinos (Unisinos). ORCID <https://orcid.org/0000-0002-7777-7884>. E-mail: catiaaf@unisinos.br.
} 


\title{
Linguagens - Revista de Letras, Artes e Comunicação - ISSN 1981- 9943 \\ Blumenau, v. 12, n. 3, p. 436-455, set./dez. 2018. \\ DOI: http://dx.doi.org/10.7867/1981-9943.2018v12n3p436-455
}

Na configuração gesto-visual há (i) sinais manuais e (ii) sinais não-manuais ${ }^{1}$, doravante Expressões Não-Manuais (ENMs). Em (i) estão presentes os movimentos de mão que poderão ser unimanuais e/ou bimanuais e em (ii) alocam-se os movimentos realizados pela cabeça, pelo tronco, pelos ombros e as expressões faciais que envolvem olhos, sobrancelhas, nariz, boca e bochechas. Ressalta-se que as expressões não-manuais coocorrem com as marcações manuais nas sentenças. Tomando como base as ENMs da Libras, Souza (2014, p. 17) afirma que

\begin{abstract}
[...] na língua de sinais, uma das diferenças, em relação às línguas orais, consiste na execução fonológica das expressões não-manuais que fazem referência à posição de cabeça, movimentação corporal e movimentação da face. Entre tais expressões encontram-se as expressões faciais que, juntamente com as expressões corporais, prestam-se a dois papéis: a marcação de construções sintáticas e a diferenciação entre itens lexicais.
\end{abstract}

Ao investigar a aprendizagem da Libras, como segunda língua (L2), por ouvintes, Souza (2009, p. 37) chama atenção para

[...] os ouvintes aprendizes de Libras apresentam maior dificuldade na aquisição da expressão facial, pois, na língua de sinais, tal marcação é de fundamental importância para o entendimento real do sinal, sendo que a entonação em língua de sinais é feita pela expressão facial, diferentemente das línguas oral-auditivas; ademais as construções sintáticas da Libras, também, são marcadas por essas expressões.

O autor apontou as principais dificuldades de ouvintes quanto à aprendizagem da Libras como L2. Porém, uma investigação mais detalhada sobre o sistema fonológico da Libras não foi contemplada, pois, segundo o próprio autor, não havia, até então, pesquisas e/ou obras que abordassem as ENMs da Libras e seu papel fonológico.

\section{FONOLOGIA NAS LÍNGUAS DE SINAIS}

Fonologia é a "ciência que estuda os sons da língua do ponto de vista de sua função no sistema de comunicação linguística” (DUBOIS et al., 1998, p. 284). Conceitos como estes em que o 'som' é tido como único objeto de pesquisa em fonologia causam certa estranheza à 'fonologia das línguas sinalizadas'. No entanto, para Karnopp (1999, p. 28), “os estudos da fonologia da língua de sinais objetivam identificar a estrutura e a organização dos constituintes fonológicos, propondo modelos descritivos e explanatórios.”

\footnotetext{
${ }^{1}$ Neste artigo, 'Expressões não-manuais’ e ‘Marcações não-manuais’ serão utilizados como sinônimos.
} 


\section{Linguagens - Revista de Letras, Artes e Comunicação - ISSN 1981- 9943 \\ Blumenau, v. 12, n. 3, p. 436-455, set./dez. 2018. \\ DOI: http://dx.doi.org/10.7867/1981-9943.2018v12n3p436-455}

Stokoe (1976) e diversos estudiosos passaram a usar o termo fonologia para investigações no âmbito das línguas de sinais, argumentando que elas são línguas naturais e que comungam de princípios linguísticos adjacentes aos das línguas orais, porém em diferentes modalidades.

Sabe-se, também, que as abordagens fonológicas recentes no tocante à língua de sinais têm considerado que a fonologia é o nível de análise gramatical onde as unidades estruturais sem significado são, de acordo com Brentari (1998), recursivamente combinadas para criar um número infinito de expressões significativas. Porém, Brentari (2007) diz, em outra definição, que o estudo fonológico das línguas de sinais focaliza mais o papel prosódico ou distributivo da fonologia para todos os tipos de representação: as não significativas e também as significativas.

Os estudos de fonologia da língua de sinais visam determinar quais são as unidades mínimas formadoras de sinais. Um dos trabalhos do investigador de uma determinada língua de sinais é identificar as configurações de mão, as locações e os movimentos que possuem caráter distintivo. Isso é realizado, comparando-se pares de sinais que contrastam minimamente, método utilizado na análise tradicional de fones distintivos das línguas naturais, conforme Quadros e Karnopp (2004).

Quanto aos sinais, os três parâmetros que os constituem configuração de mão (CM), ponto de articulação (PA) e movimento (M) não atribuem significados quando isolados. Uma configuração de mão e um mesmo movimento, mas com locação diferente, poderá resultar em uma mudança de significado, formando assim um par mínimo. De acordo Quadros e Karnopp (2004), a diferença crucial estabelecida entre línguas orais e línguas de sinais está na presença da ordem linear entre os fonemas das línguas orais e sua ausência nas línguas de sinais, cujos fonemas são articulados simultaneamente. Souza (2014) diz que a diferença básica entre língua de sinais e língua falada diz respeito à estrutura simultânea da organização dos elementos das línguas de sinais. Enquanto as línguas orais são lineares, isto é, apresentam uma ordem linear entre os fonemas, as línguas de sinais, além da linearidade, articulam os fonemas simultaneamente, como se vê nos esquemas 1 e 2. 


\section{Linguagens - Revista de Letras, Artes e Comunicação - ISSN 1981- 9943 \\ Blumenau, v. 12, n. 3, p. 436-455, set./dez. 2018. \\ DOI: http://dx.doi.org/10.7867/1981-9943.2018v12n3p436-455}

Esquema 1. Língua Oral

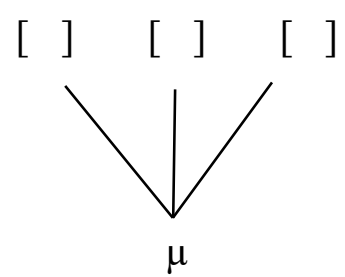

Fonte: Quadros e Karnopp (2004, p. 49).

Esquema 2. Língua Não-Oral

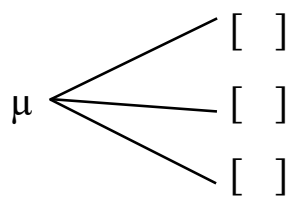

Fonte: Quadros e Karnopp (2004, p. 49).

Para as autoras, na figura 1, a horizontalidade indica sucessão temporal característica das línguas orais, enquanto o alinhamento vertical, na figura 2, remete à simultaneidade temporal, evidenciada nas línguas de sinais; $\mu$ representa morfema; [ ] equivale a um fonema ou conjunto de especificações. Souza (2014, p. 24) afirma que

\footnotetext{
o desenvolvimento de modelos fonológicos, a partir de Stokoe (1960), apresenta a introdução da noção de ordem linear, mostrando a sequência das unidades que constituem os sinais e um aperfeiçoamento dos parâmetros e das relações estruturais entre tais unidades na descrição fonológica dos sinais. Além dos parâmetros fonológicos de CM, L e M, estudos mais recentes sobre as línguas de sinais adicionam à fonologia das línguas de sinais a orientação de mão e as marcações não-manuais.
}

Ao estudar as línguas de sinais, Ferreira-Brito (1995) classificou CM, PA ${ }^{3}$ e M como parâmetros primários e a região de contato, a orientação das mãos e a disposição delas como parâmetros secundários. A autora, em adição a isso, dá um significado aos componentes nãomanuais, pois, segundo ela, são elementos de grande relevância ao lado dos parâmetros primários e secundários (FERREIRA-BRITO, 1995).

Algumas informações sobre especificidades das ENMs serão consideradas no próximo tópico.

\footnotetext{
${ }^{3}$ Ponto de articulação refere-se, também, ao parâmetro de locação.
} 


\section{Linguagens - Revista de Letras, Artes e Comunicação - ISSN 1981- 9943 \\ Blumenau, v. 12, n. 3, p. 436-455, set./dez. 2018. \\ DOI: http://dx.doi.org/10.7867/1981-9943.2018v12n3p436-455}

\section{EXPRESSÕES NÃO-MANUAIS (ENMS)}

Os seres humanos utilizam as ENMs (expressões faciais, movimentos corpóreos) para se comunicar tanto em línguas orais quanto nas línguas de sinais. Muitas dessas expressões são universais e servem, em alguns casos, para salientar propósitos emocionais.

Mineiro e Colaço (2010) relatam que a comunicação humana por intermédio das ENMs é um recurso disponibilizado quando se perde a comunicação verbal, em casos patológicos e, também, elucidam que as ENMs são vistas, nesse caso, como uma ponte entre aquele que perdeu, literalmente, 'o verbo' e o mundo que o rodeia.

Nas línguas de sinais, com destaque à Libras, o uso das ENMs é visto como um recurso dado pelo próprio sistema da língua. Sandler e Lillo Martin (2006) defendem que as ENMs são empregadas de duas formas: uma não linguística e outra linguística, classificando-as como traços prosódicos de entonação em línguas de sinais - suprassegmentais que contêm marcas de duração, tom e intensidade - da mesma maneira que pesquisadores de línguas orais têm classificado as expressões faciais (EFs) em línguas faladas.

Investigações acerca das EMNs da American Sign Language (ASL) revelaram a existência de diferentes comportamentos para expressões afetivas ou gramaticais (REILLY; MCLNTIRE; SEAGO, 1992; REILLY, 2006; ELFENBEIN, 2013). Para Reilly (2006), embora os músculos faciais utilizados para a demonstração de emoções sejam os mesmos acionados para o desempenho de questões linguísticas, o comportamento emocional-afetivo não precisa necessariamente da linguagem, enquanto ENMs linguísticas geralmente coocorrem com a realização dos sinais.

A posição da cabeça, do corpo, da sobrancelha e da testa, do nariz, o olhar e as bochechas nos dão informações de itens lexicais ou indicam o começo ou o final de uma oração. Um maior detalhamento das formas e/ou tipos das ENMs da Libras estão no esquema 3: 
Linguagens - Revista de Letras, Artes e Comunicação - ISSN 1981- 9943
Blumenau, v. 12, n. 3, p. 436-455, set./dez. 2018.

DOI: http://dx.doi.org/10.7867/1981-9943.2018v12n3p436-455

Esquema 3. Expressões não-manuais

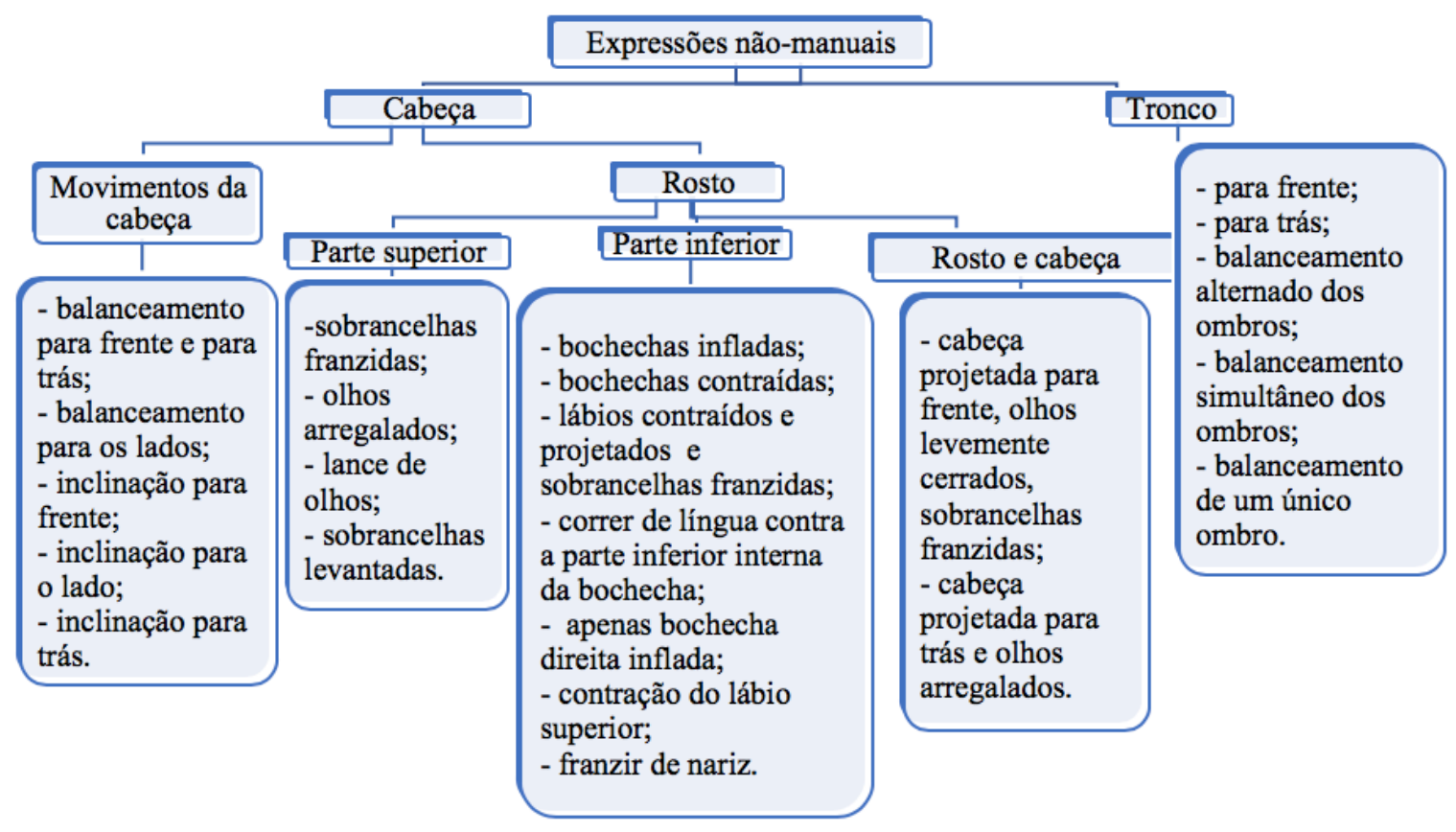

Fonte: Souza (2020), adaptado de Brito e Langevin (1995).

Conforme se vê no Esquema 3, é variado o número de ENMs na Língua Brasileira de Sinais. Duas ENMs podem ocorrer simultaneamente. A citar, em Libras, a interrogação e a negação podem ser expressas juntas, balançando-se a cabeça para os lados, franzindo-se as sobrancelhas e movendo-se o tronco à frente, e inclinando-se finalmente a cabeça para trás, conforme ilustra a figura 1 .

Figura 1. Sinalização de PARA MIM?

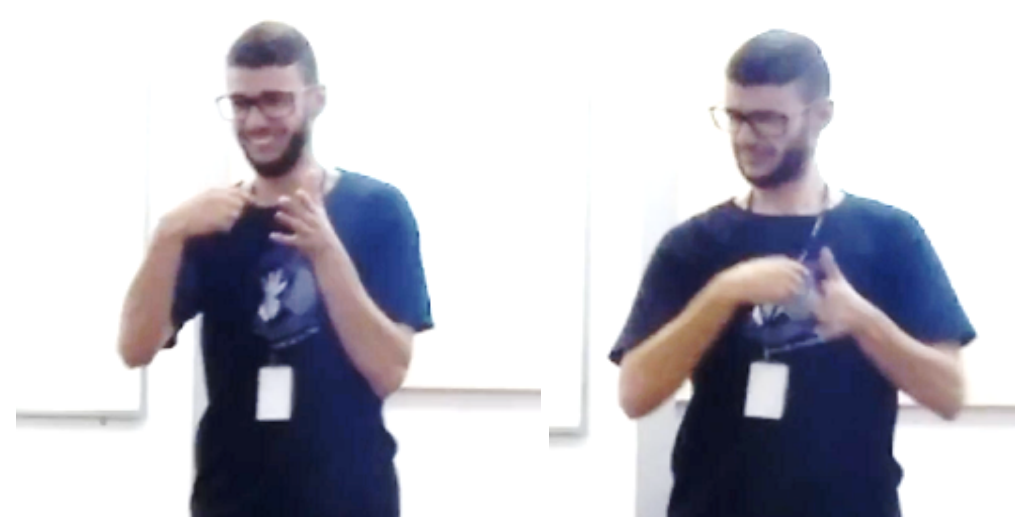

Fonte: os autores (2020). 


\section{Linguagens - Revista de Letras, Artes e Comunicação - ISSN 1981- 9943 \\ Blumenau, v. 12, n. 3, p. 436-455, set./dez. 2018. \\ DOI: http://dx.doi.org/10.7867/1981-9943.2018v12n3p436-455}

Em "PARA MIM?", há o franzimento das sobrancelhas, seguido por um breve abaixamento de cabeça. Os detalhes das expressões permitem ver que o sinalizador, em um primeiro momento, faz o franzimento das sobrancelhas e, após, projeta sua cabeça a fim de pontuar a forma interrogativa dentro do contexto oracional.

Movimentos e configurações não-manuais também são adicionados às ENMs, sobrancelhas franzidas, lance de olhos, bochechas infladas, contração labial, balanço e inclinação de cabeça, movimentos de tronco, entre outros. Esses são alguns movimentos que, dependendo da forma e do momento em que são executados, são responsáveis por diferenças de sentido em sentenças da Libras. Salienta-se que a posição da cabeça, a posição do corpo, da sobrancelha e da testa, do nariz, o olhar, as bochechas nos dão informações de itens lexicais ou indicam o começo ou final de uma oração. Liddel (1978, apud ARAÚJO, 2013, p. 29) elucida que

[...] a parte superior da face e a cabeça detêm expressão não-manual para as orações interrogativas: uma sentença construída com a cabeça e ombros inclinados para frente e sobrancelhas levantadas, por exemplo, é interpretada como uma interrogativa que requer uma resposta "sim" ou "não".

Essa afirmação já havia sido vivenciada por Souza (2009), ao observar a produção de frases interrogativas associadas a frases negativas e exclamativas por ouvintes em processo de aquisição da Libras como L2. De acordo com suas constatações, os participantes do estudo apresentaram dificuldades na simultaneidade entre as diferentes expressões faciais exigidas pelo enunciado.

O autor, em outra ocasião, diz que expressões não-manuais diferem o significado de alguns sinais que possuem a execução manual idêntica, como em SILÊNCIO e PARAR (Souza, 2009). O primeiro vocábulo deve ser sinalizado com o dedo indicador sobre a boca, com uma expressão calma e serena; ao utilizar a mesma configuração de mão, mas com um movimento mais rápido e com uma expressão de zanga, seu significado torna-se “Cale a boca!". O segundo vocábulo deve ser executado com a mão aberta, em movimento brusco e com expressão séria; o mesmo sinal, porém com um movimento lento e com uma expressão facial de tranquilidade, representará "calma". Como se pode observar, a ENM assume o papel de, em algumas sentenças e palavras, atribuir carga semântica e sintática.

É preciso destacar também que a EF gramatical é linguisticamente determinada: começa um pouco antes de se iniciar o sinal manual, alcança o ápice da intensidade durante o sinal e termina antes que o próximo sinal comece, como afirma Araújo (2013). As EFs na Libras estão presentes em diferentes tipos frasais e, em cada modelo de frase, elas desempenham funções 


\section{Linguagens - Revista de Letras, Artes e Comunicação - ISSN 1981- 9943 \\ Blumenau, v. 12, n. 3, p. 436-455, set./dez. 2018. \\ DOI: http://dx.doi.org/10.7867/1981-9943.2018v12n3p436-455}

distintas dentro do ato comunicativo. Fazer a descrição e a análise das ENMs, com destaque às EFs da Libras, são de suma importância para o conhecimento da língua e do seu funcionamento enquanto sistema linguístico.

Embora seja possível notar a complexibilidade do sistema fonológico da Libras (aqui apresentadas as ENMs), estudos que façam levantamento, descrições e análises das marcações não-manuais, com foco no papel fonológico, são escassos e, como observado de acordo com o recorte dado pelo pesquisador, inexistentes.

O próximo tópico trará um maior detalhamento das pesquisas diretas ou indiretas sobre as ENMs da Libras. Ressalta-se que (i) pela inacessibilidade a estudos ainda não publicados até a análise final do corpus e (ii) por haver pesquisas ainda em desenvolvimento, nem todos os trabalhos serão apresentados neste artigo.

\section{4 (RE)VISITANDO AS ENMs: PROCEDIMENTO METODOLÓGICO E DADOS PRÉVIOS}

Como já foi apontado, a literatura afirma a real importância das ENMs da Libras, porém sua abrangência, considerando o âmbito desse estudo, é pequena e parece insuficiente frente à especificidade do tema. Pesquisas desenvolvidas a partir desta perspectiva são restritas. Diante disso, viu-se a necessidade de fazer um levantamento das obras que abordam as ENMs da Libras e estabelecer um 'diálogo' entre autores que têm como objeto de investigação as expressões não-manuais.

Com isso, realizou-se um rastreamento de pesquisas que possuem a Libras como estudo, focando nesse tipo de expressão. A seleção das obras deu-se tanto em materiais impressos, como em estudos disponíveis na rede mundial de computadores, a partir da qual esta descrição se constituiu. Buscas em portais de periódicos e em sítios de grandes universidades foram realizadas. Com isso, obteve-se acesso a monografias, artigos, dissertações e teses que apresentavam como tema ENMs na língua de sinais brasileira.

Palavras-chave amplas foram criadas como uma espécie de filtro para a escolha dos trabalhos. Os vocábulos apresentados no Quadro 1 parecem contemplar as entradas lexicais relacionadas às ENMs já vistas anteriormente. Ressalta-se a importância do uso do termo 'Libras', uma vez que é este o sistema linguístico que interessa no âmbito desta pesquisa.

Quadro 1. Expressões de busca e obras encontradas 
Linguagens - Revista de Letras, Artes e Comunicação - ISSN 1981- 9943

Blumenau, v. 12, n. 3, p. 436-455, set./dez. 2018.

DOI: http://dx.doi.org/10.7867/1981-9943.2018v12n3p436-455

\begin{tabular}{|c|}
\hline EXPRESSÕES \\
DE BUSCA \\
\hline Expressão facial da Libras \\
\hline Expressões não-manuais da Libras \\
\hline Marcação não-manual da Libras \\
\hline Interrogação na Libras \\
\hline Negação na Libras \\
\hline Fonologia da Libras \\
\hline Prosódia da Libras \\
\hline Constituintes prosódicos da Libras
\end{tabular}

Fonte: Os autores (2020).

Os vocábulos apresentados no Quadro 1 revelaram a aparição de cinquenta e quatro trabalhos com referência às ENMs. O quadro 2 exemplifica o tratamento dado às obras encontradas que permitiu o cruzamento de informações.

Quadro 2. Exemplo de tabulação dos dados

\begin{tabular}{|l|c|l|}
\hline AUTOR & ANO & BREVE RESUMO \\
\hline KARNOPP, L. B. & 1999 & $\begin{array}{l}\text { A tese aborda a produção dos primeiros sinais na } \\
\text { Libras e tem como foco a aquisição fonológica de } \\
\text { CM, L e M por uma criança surda, filha de surdos, } \\
\text { no período de 8 aos 30 meses de idade. [...] }\end{array}$ \\
\hline ARROTEIA, J. & 2005 & $\begin{array}{l}\text { Esta dissertação teve como meta a descrição dos } \\
\text { elementos que marcam ou contribuem de alguma } \\
\text { forma para o real entendimento das sentenças em } \\
\text { Libras. Chamou a atenção o fato de haver marcas } \\
\text { negativas nos dois componentes da língua, manual } \\
\text { (NÃO e NADA) e não-manual. [... }\end{array}$ \\
\hline
\end{tabular}

Fonte: Souza (2014, p. 75).

O quadro 2, então, traz informações sucintas de pesquisas que abordam, de alguma maneira, as ENMs Libras. Ressalta-se que esse levantamento foi realizado com cada obra encontrada. Por meio da busca nas bases de dados encontramos o primeiro estudo com o tema 'aquisição fonológica da Libras', realizado por Karnopp (1999), a partir do qual, acredita-se, outros trabalhos foram escritos com base neste tema. Tal constatação levou à adição do quesito cronológico à busca. 


\section{Linguagens - Revista de Letras, Artes e Comunicação - ISSN 1981- 9943 \\ Blumenau, v. 12, n. 3, p. 436-455, set./dez. 2018. \\ DOI: http://dx.doi.org/10.7867/1981-9943.2018v12n3p436-455}

É preciso referir ainda que as palavras-chave, em grande parte, estavam inseridas no texto e não, como esperado, nos títulos e/ou nas indicações dos termos-chave definidos pelos autores. Assim, é possível afirmar que, esse tema foi discutido brevemente dentro do estudo e por isso, uma indicação nas palavras-chave não seria plausível. Contudo, a limitação poderá ter ocorrido na escolha dos termos-chave por nós realizada e, talvez, outras seleções de termos de busca pudessem ter sido feitas para que fossem obtidas mais produções sobre o tema. Desde já, aponta-se esse dado como sugestão para trabalhos futuros.

Por meio das buscas realizadas pela rede mundial de computadores, como já foi mencionado, as investigações sobre a fonologia da Libras iniciaram, timidamente, no final da década de 90. Constatou-se que um aumento significativo de estudos sobre as ENMs ocorreu no ano de 2008, com a publicação de quatro trabalhos, atingindo seu ápice nos anos de 2013 e 2018, com a publicação de sete pesquisas em ambos os anos. O Gráfico 1 ilustra essas observações.

Gráfico 1. Avanço frente às investigações das expressões não-manuais

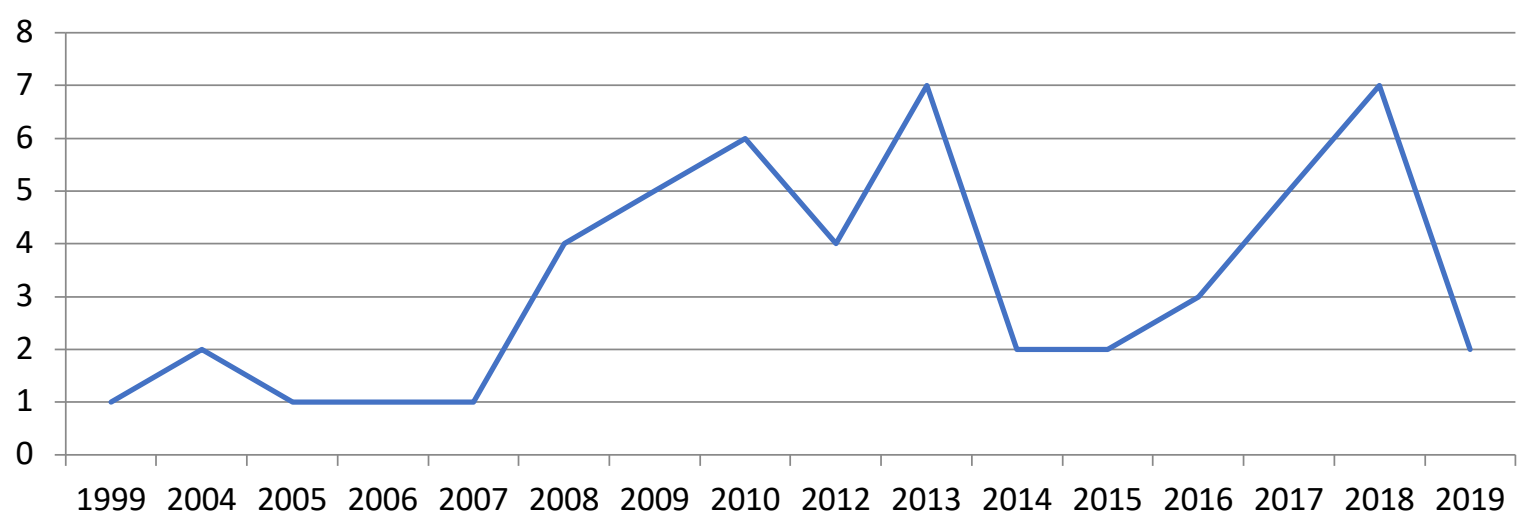

Fonte: Os autores (2020).

Em 2012, três trabalhos foram escritos. Em 2014 e 2015 defesas de dissertações e teses ocorreram, porém apenas uma dissertação focou na fonologia da Libras. Os estudos resultantes da busca estão disponíveis em meio eletrônico e impresso. Ressalta-se que o corpus desta investigação se constituiu em grande parte por dissertações de mestrado e por artigos, o que pode indicar a força da produção acadêmica nos programas de pós-graduação, ou seja, há interesse na pesquisa por diversas razões, como já foi comentado. Entretanto aponta-se a necessidade de uma pesquisa que investigue as razões pelas quais estes tipos de trabalhos acadêmicos têm privilegiado mais a discussão desse tema do que outros. 


\section{Linguagens - Revista de Letras, Artes e Comunicação - ISSN 1981- 9943 \\ Blumenau, v. 12, n. 3, p. 436-455, set./dez. 2018. \\ DOI: http://dx.doi.org/10.7867/1981-9943.2018v12n3p436-455}

No próximo tópico, estabelecem-se comparações entre as obras pesquisadas no que se refere às ENMs.

\section{DESTAQUES SOBRE ESTUDOS QUE SE VOLTARAM ÀS ENMS NO PERÍODO DE 1999 a 2019}

Como mencionado, investigações que têm como tema ENMs trazem informações singelas ou restritas frente à especificidade do tema. Apresentam-se, nesta seção, considerações relevantes encontradas em alguns estudos realizados.

Faz-se importante mencionar o trabalho de Karnopp (1999), considerado um marco nos estudos linguísticos da Libras, já que a autora traz as pressuposições básicas sobre as ENMs. Esta investigação, como discutido em seções anteriores, foi um dos estudos precursores ao trazer uma pequena seção direcionada às ENMs. Considera-se que o tema foi pouco explorado pela autora, por não ter sido o foco do estudo naquele momento.

Assim como Karnopp (1999), Brito (2010) diz que ENMs são responsáveis pelas marcações sintáticas e pela diferenciação entre itens lexicais. Em relação a este último item, Souza (2008), em sua pesquisa sobre as dificuldades apontadas por ouvintes na aprendizagem da Libras, afirma que os aprendizes ouvintes deparam-se com obstáculos na aprendizagem das expressões faciais. Embora o autor tenha como tema principal a aquisição da fonologia da Libras por ouvintes, o capítulo que aborda as ENMs também é sucinto e traz ideias já apontadas por Karnopp (1999).

Arroteia (2005), ao investigar o papel da marcação não-manual nas sentenças negativas, apresenta uma descrição detalhada sobre expressões faciais sintáticas responsáveis pela marcação da negação em Libras. Apesar da ciência da pesquisadora quanto ao fato de que os marcadores não-manuais de negação se encontram inseridos nas ENMs, em seu trabalho não se verifica uma definição clara sobre tais expressões.

Xavier (2006), ao tentar descrever unidades do nível fonético-fonológico, apresenta uma seção dedicada às ENMs, contudo, as afirmações e constatações feitas pelo autor já foram, de certo modo, contempladas por Karnopp (1999).

O software F-LIBRAS, proposto por Baptista (2007), teria a função de suprir as dificuldades comunicacionais entre pessoas surdas e ouvintes. Em seu estudo, Baptista (2007) apresenta uma sucinta reflexão acerca das marcações não-manuais, com foco nas expressões faciais. 


\section{Linguagens - Revista de Letras, Artes e Comunicação - ISSN 1981- 9943 \\ Blumenau, v. 12, n. 3, p. 436-455, set./dez. 2018. \\ DOI: http://dx.doi.org/10.7867/1981-9943.2018v12n3p436-455}

Junior (2008), ao criar o Tree-Libras, programa cuja função é auxiliar o aprendizado da Libras por surdos, traz um capítulo sobre as ENMs, com foco nas expressões faciais. O autor aborda as diferenças entre expressões faciais afetivas e expressões faciais que desempenham papéis sintáticos. As informações trazidas pelo autor são relevantes, porém uma abordagem mais detalhada sobre as ENMs não foi realizada.

A fim de corroborar com as informações, Temóteo (2008) apresenta exemplos de expressões faciais que marcam sentenças interrogativas. No que diz respeito à teorização, não é realizado detalhamento das funções exercidas pelas ENMs.

Leite (2008) apresenta uma explicação e definição sobre o papel que as expressões faciais desempenham no enunciado, acrescentando uma nova informação: a divisão de regiões da face. O autor propõe que expressões realizadas pela parte inferior do rosto estão associadas a itens lexicais ou a sintagmas (LEITE, 2008). Enquanto as partes superior e inferior do rosto estão relacionadas a diferentes domínios sintáticos - sinais realizados na região superior do rosto ou a cabeça ocorreriam com constituintes maiores, tais como orações e sentenças. Segundo o autor, essas regiões evidenciam expressões faciais para sentenças interrogativas, pois uma sentença estabelecida com a cabeça e ombros inclinados para frente e com as sobrancelhas levantadas é interpretada como uma interrogativa que terá como resposta um 'sim' ou um 'não' (LEITE, 2008).

Souza (2009) apresenta uma teorização sobre ENMs, também calcado em Karnopp (1999), com foco nas marcações frasais da Libras.

Direcionada à formação de novos professores de Libras, Quadros (2009), em parceria com a Universidade Federal de Santa Catarina, apresenta um material voltado aos alunos do curso de licenciatura Letras Libras. No material didático, a autora traz questões como o status da Libras como língua natural, as propriedades da língua de sinais e sua fonologia.

Ribeiro (2009) apresenta uma pesquisa sobre a constituição sígnica da Língua Brasileira de Sinais. De acordo com a autora, a fonologia na língua de sinais busca identificar a estrutura e organização de seus constituintes fonológicos. Ao abordar aspectos relacionados às ENMs, Ribeiro (2009) faz elucidações acerca das expressões faciais, porém sua abordagem dentro do estudo é perene.

Ao abordar que ENMs integram os parâmetros secundários da Libras, Diniz (2010) relata que as expressões faciais, as posturas corpóreas e outras ENMs fazem parte dos parâmetros secundários por meio dos quais são expressas as informações gramaticais. Por não ser o objeto de pesquisa da autora, não são apresentadas maiores explicações destas marcações. 


\title{
Linguagens - Revista de Letras, Artes e Comunicação - ISSN 1981- 9943 \\ Blumenau, v. 12, n. 3, p. 436-455, set./dez. 2018. \\ DOI: http://dx.doi.org/10.7867/1981-9943.2018v12n3p436-455
}

Voltado à aquisição da Libras por crianças surdas, o estudo de Bento (2010) surge com uma detalhada visão sobre o sistema fonológico da Libras. Ao mencionar as ENMs, uma série de figuras que demonstram os graus de intensidade revelados pelas expressões faciais é apresentada, e o autor mantém as afirmações já feitas por Karnopp (1999).

Ao falar sobre os poucos estudos existentes quanto às ENMs, Souza $(2014$, p. 88) diz que:

\begin{abstract}
Acredita-se que um ponto importante abordado quanto às ENMs é a falta de estudos detalhados acerca do tema. Essa forte afirmação está disponível no Manual produzido pela Universidade Federal de Santa Catarina, no ano de 2010. A fim de esclarecimentos, o manual, voltado à formação de novos professores de Libras, recebeu o nome de Libras II. Neste material online, o tema explicitado refere-se às expressões faciais gramaticais, ditas como marcações não-manuais. De forma bastante interativa e lúdica, a autora apresenta as expressões faciais responsáveis pelos tipos frasais na Libras; no entanto, quanto à sistematização das ENMs, o manual elucida que ainda não há estudos suficientes sobre as expressões não-manuais na Libras. Com isso percebe-se que um maior detalhamento sobre parâmetros secundários se torna necessário frente aos estudos linguísticos.
\end{abstract}

Rosa (2010) também apresenta questões fonológicas relacionadas aos parâmetros primários da Libras. No tangente às ENMs, a autora detém-se nas informações já recorrentes nesta discussão.

Em sua pesquisa sobre variação fonológica na Libras, Xavier (2011) compartilha vários exemplos de parâmetros primários. Ao se dedicar às ENMs da Libras, com foco nas expressões faciais, o autor adota a postura que permeia grande parte dos estudos: uma breve reflexão dos parâmetros secundários.

Santos (2012), em seu estudo comparativo entre Língua Portuguesa e Língua Brasileira de Sinais, faz uma reflexão sobre os parâmetros primários da Libras, contudo, não faz menção às ENMs.

Araújo (2013) apresenta uma investigação contrastiva entre as ENMs e as marcas nãomanuais na Libras, propondo uma diferenciação entre os 'dois constituintes'. Segundo Araújo (2013), o uso de componentes não-manuais poderá diferenciar significados (como já dito anteriormente) e sentenças em nível fonológico, morfológico e sintático. Diferentemente das pesquisas apresentadas, a autora não optou pelo detalhamento dos parâmetros primários.

Com um olhar para os sinais não-manuais gramaticais da Libras, Pêgo (2013) apresenta detalhamento das funções das ENMs referentes aos traços morfológicos, lexicais e sintáticos. Seu estudo traz como contrapartida as investigações da American Sign Language (ASL). A autora salientou a busca, exaustiva, de trabalhos que envolvessem análises morfológicas das expressões faciais na Libras. Entretanto, como ela destaca, um maior detalhamento não foi 


\section{Linguagens - Revista de Letras, Artes e Comunicação - ISSN 1981- 9943 \\ Blumenau, v. 12, n. 3, p. 436-455, set./dez. 2018. \\ DOI: http://dx.doi.org/10.7867/1981-9943.2018v12n3p436-455}

possível, pois nenhum trabalho que descrevesse as funções morfológicas das ENMs foi encontrado (PÊGO, 2013).

Talvez pela pouca literatura existente sobre as ENMs da Libras e/ou apenas pelo foco de sua pesquisa, Leite (2013), em seu trabalho sobre a identificação de unidades gramaticais na Libras, não aborda de forma sistemática as ENMs. O pesquisador faz uma menção sobre o sistema que usou para transcrever os dados sobre Articuladores não-manuais transcritos acima da linha das glosas. No entanto, uma abordagem mais apurada das funções que as ENMs possuem não foi realizada.

Silva (2013) desenvolveu um estudo sobre a atuação do intérprete de Libras no Ensino Superior, no qual menciona a necessidade de domínio que o intérprete precisa ter dos parâmetros primários e secundários. Ela apresenta uma descrição dos parâmetros fonológicos da Libras, contudo, não estabelece relações explícitas com as ENMs ao referir-se aos parâmetros secundários.

Felipe (2013) vale-se de uma abordagem mais completa em relação ao estudo anterior, pois, ao ter como foco o discurso verbo-visual na Libras, propõe uma diferenciação entre expressões afetivas, comunicações paralinguísticas complementares em um enunciado e as marcas verbo-visuais gramaticais, não detalhadas em seu trabalho. Felipe (2013) afirma que as pesquisas sobre as expressões faciais e outras ENMs iniciaram com Liddell, no ano de 1978. Em Felipe (2013), portanto, há maior detalhamento das marcas fonológicas das ENMs, das marcas morfológicas, das marcas sintáticas e das marcas discursivas.

Almeida (2013) investigou tópicos sintáticos da Libras, passando pelo conceito geral de sintaxe das línguas de sinais. Direcionando seu estudo à sintaxe da Libras, o autor se mantém nas marcações não-manuais que determinam tipos frasais na língua de sinais. Do ponto de vista teórico, Almeida (2013) traz, também, os preceitos inicialmente trabalhados por Karnopp (1999) e por Felipe (2006), de acordo com sua trajetória nos estudos linguísticos sobre a Libras.

Souza e Lima (2014) apresenta uma proposta de glossário da Libras para a área do desenho arquitetônico. Em seu trabalho, a autora resgata alguns pressupostos linguísticos basilares para o estudo da língua de sinais. Na subseção dedicada às ENMs, ela afirma que esse parâmetro linguístico relacionado às expressões não-manuais, está veiculado à prosódia da Libras (SOUZA E LIMA, 2014), porém um maior aprofundamento teórico não é realizado.

Xavier e Barbosa (2014) realizam um estudo de variação na produção de sinais, cuja análise possibilitou ver que há evidências de variação nos parâmetros manuais e não-manuais 


\section{Linguagens - Revista de Letras, Artes e Comunicação - ISSN 1981- 9943 \\ Blumenau, v. 12, n. 3, p. 436-455, set./dez. 2018. \\ DOI: http://dx.doi.org/10.7867/1981-9943.2018v12n3p436-455}

inter-sujeito. Por se tratar de um estudo preliminar, não foram possíveis maiores constatações sobre a presença das ENMs na variedade da Libras.

Freitas (2015) faz uma reflexão bastante pertinente sobre os níveis sintático e morfológico da Libras, com destaque às ENMs. Para o autor, essas expressões são de extrema relevância em língua de sinais, pois corroboram na formação da sua estrutura gramatical. Frente a isso, o estudo traz uma tentativa de criação de modelos automáticos de reconhecimento de ENMs, com destaque às expressões faciais gramaticais, com intuito de auxiliar técnicas de aprendizado da Libras.

Entre 2015 e 2017, constatou-se um aumento significativo em trabalhos acadêmicos que investigaram direta ou indiretamente questões culturais ligadas às comunidades surdas, línguas de sinais, processos de aprendizagem da Libras e ensino de língua portuguesa como L2 para surdos.

Os dados analisados permitiram constatar que, do final de 2017 a meados de 2019, as expressões não-manuais começaram a ganhar novamente espaço dentro dos estudos linguísticos da Libras. Embora haja trabalhos que apenas reproduziram as informações já existentes, Xavier (2019), por exemplo, adiciona uma proposta de análise de ENMs lexicais. O autor analisou 368 sinais da Libras que foram extraídos do banco de dados de Xavier (2006), constituído com base no dicionário de Capovilla e Raphael (2001). Após as análises, Xavier (2019) concluiu que nem todas as expressões não-manuais que estavam listadas nas descrições dos sinais analisados eram de fato lexicais, pois muitas delas possuíam características prosódicas e/ou sintáticas.

Após retomar as considerações feitas pelos autores pesquisados neste estudo e traçar similitudes frente às definições e/ou apresentações deles, nota-se que, até meados de 2014, as acepções acerca das expressões não-manuais são, em sua maioria, superficiais. No entanto, nota-se que, ainda naquele ano, a produção intelectual sobre as ENMs passou a ter algumas de suas funções descobertas e o conceito de variação começou a ser desvendado, como em Xavier e Barbosa (2014).

Ao estudar mais profundamente as obras aqui citadas, notou-se que os termos utilizados para a busca dos dados, muitas vezes são utilizados, nos trabalhos investigados, como sinônimos, independentemente de exercerem funções gramaticais ou não; talvez o uso indiscriminado dessas expressões, sem as delimitações existentes, não corrobore para um detalhamento mais apurado sobre as ENMs. 


\section{Linguagens - Revista de Letras, Artes e Comunicação - ISSN 1981- 9943 \\ Blumenau, v. 12, n. 3, p. 436-455, set./dez. 2018. \\ DOI: http://dx.doi.org/10.7867/1981-9943.2018v12n3p436-455}

Pode-se dizer, ao final desta reflexão, que foi possível desenhar um cenário acerca das informações e dados acessados que, de certa forma, constitui-se um corpus de pesquisa para futuros resultados e/ou inovações frente ao objeto de estudo.

\section{CONSIDERAÇÕES FINAIS}

Primeiramente, faz-se necessário ressaltar que as pesquisas aqui mencionadas são de grande valia para os estudos das línguas de sinais, sobretudo da Libras. Em nenhum momento houve a intenção de invalidar as investigações e, tampouco, seus autores.

Agora voltando-se às considerações, pode-se dizer que, de certa forma, os estudos aqui apresentados (1999 - 2019) pareciam não avançar significativamente em relação à construção de novos conhecimentos sobre as ENMs, já que apenas reiteravam as afirmações feitas por Karnopp (1999). Entretanto, em 2014, esse cenário começou a apresentar modificações lentas e gradativas, talvez por conta da escassez de estudos. Além disso, como explicitado por Pêgo (2013), muitas pesquisas linguísticas com foco na Libras valem-se dos estudos da $A S L$.

As ENMs são elementos de suma importância ao lado dos parâmetros primários, já que, conforme Brito (2010), parâmetros secundários, como as ENMs, estão presentes na organização fonológica dos sinais. Embora muitos dos estudos abordados neste artigo concordem com essa afirmação, o que se constatou foi um maior detalhamento dos parâmetros primários, e, algumas vezes, pouca ou nenhuma descrição dos parâmetros secundários (ENMs). Provavelmente, o maior detalhamento dos parâmetros primários deva-se aos estudos já existentes na $A S L$ que, em comparação às investigações sobre as ENMs, são mais numerosos. Em decorrência disso, estudos contrastivos entre a Libras e a $A S L$ foram realizados com a intenção de um maior entendimento dos parâmetros fonológicos existentes nas línguas de sinais.

Outro ponto a ser discutido é que as pesquisas com foco na sintaxe, aqui analisadas, apresentaram dados em que o papel das ENMs parecia ser unicamente a marcação de tipos frasais. Embora seus autores afirmassem que as ENMs marcam construções sintáticas como orações relativas, topicalizações, concordância e foco, e constituintes prosódicos nenhum desses aspectos chegou a ser desenvolvido, com exceção de Xavier (2019).

No que tange às ENMs, em estudos que possuem como tema 'a negação da Libras', percebeu-se um maior detalhamento das expressões faciais de negação. Isso também pode 


\section{Linguagens - Revista de Letras, Artes e Comunicação - ISSN 1981- 9943 \\ Blumenau, v. 12, n. 3, p. 436-455, set./dez. 2018. \\ DOI: http://dx.doi.org/10.7867/1981-9943.2018v12n3p436-455}

ocorrer devido à literatura existente sobre a marcação não-manual em línguas de sinais favorecer uma análise gramatical desta marcação como um todo (ARROTÉIA, 2005.)

Ao ver detalhadamente as obras aqui apresentadas, outra constatação foi feita: nos anos de 2013 e 2018 houve um aumento significativo de pesquisas com foco nas ENMs, e grande parte delas são dissertações de mestrado. Pôde-se perceber que a literatura existente é restrita e, muitas vezes, inexistente, conforme Pêgo (2013). Porém, com advento das línguas de sinais e com a inserção do surdo na sociedade ouvinte, investigações sobre algumas especificidades da Libras, a citar ENMs, começaram a ser (re)descobertas, como se viu no presente trabalho.

\section{REFERÊNCIAS}

ALMEIDA, M. P. de. Tópicos linguísticos: sintaxe na Libras. In: Revista Philologus, p. 01$681,2013$.

ANATER, G. I. P. As marcações linguísticas não-manuais na aquisição da Língua de sinais brasileira (lsb): um estudo de caso Longitudinal. Dissertação (Mestrado)-. Centro de comunicação e expressão, UFSC, Florianópolis. 2009.

ARAÚJO, A. D. S. As expressões e as marcas não-manuais na Língua de Sinais

Brasileira. Dissertação (Mestrado), Universidade de Brasília, Brasília, 2013.

ARROTÉIA, J. O papel da marcação não-manual nas sentenças negativas em Língua de Sinais Brasileira (LSB). Dissertação (Mestrado), Universidade Estadual de Campinas, Campinas, São Paulo, 2005.

BAPTISTA, F. F- Libras Ambiente Integrado de Ensino-Aprendizagem para Língua Brasileira de Sinais. Dissertação (Mestrado), Centro Universitário Eurípides de Marília, Marília, 2007.

BENTO, N. A. Os parâmetros fonológicos: configuração de mãos, ponto de articulação e movimento na aquisição da Língua Brasileira de Sinais - um estudo de caso. Dissertação (Mestrado em Letras), Universidade Federal da Bahia, Salvador, 2010.

BRENTARI, D. A prosodic model of Sign Language Phonology. Cambridge, MA: MIT Press, 1998.

Sign language phonology: Issues of iconicity and universality. In:

PIZZUTO, E.; PIETRANDREA, P.; SIMONE, R. (Org.). Verbal and Signed Languages. Berlin: Mouton de Gruyter, p. 59-80, 2007.

BRITO, L.F. Por uma gramática de língua de sinais. Rio de Janeiro: Tempo Brasileiro, 2010. 
DINIZ, H. G. A história da Libras: um estudo descritivo das mudanças fonológicas e lexicais. Dissertação (Mestrado), Universidade Federal de Santa Catarina, Florianópolis, 2010.

DUBOIS, J. et al. Dicionário de linguística. São Paulo: Cultrix, 1998.

ELFENBEIN, H. A. Nonverbal dialects and accents in facial expressions of emotion. [Manuscrito]. Emotion Review. 2013. Disponível em:

https://www.researchgate.net/publication/273134402_Nonverbal_Dialects_and_Accents_in_F acial_Expressions_of_Emotion. Acesso em: 03/03/2020.

FELIPE, T. A. Libras em Contexto: curso básico. Ministério da Educação, Secretaria de Educação Especial. Brasília, 2006.

O discurso verbo-visual na língua brasileira de sinais -Libras. In:

Bakhtiniana, Rev. Estud. Discurso, p. 67-89, 2013.

FERREIRA-BRITO, L.; LANGEVIN, E. Sistema Ferreira Brito-Langevin de Transcrição de Sinais. In: FERREIRA-BRITO, L. Por uma gramática de línguas de sinais. Rio de Janeiro: Tempo Brasileiro, 1995.

FREITAS, F. A. Reconhecimento automático de expressões faciais gramaticais na língua brasileira de sinais. Dissertação (Mestrado em Ciências), Universidade de São Paulo, São Paulo, 2015.

JUNIOR, R. C. Tree-Libras: especificação da tradução da língua portuguesa para Libras. Monografia (Graduação em Ciências da computação), Centro Universitário Eurípedes de Marília, Marília, 2008.

KARNOPP, L. B. Aquisição do parâmetro configuração de mão dos sinais da LIBRAS: estudo sobre quatro crianças surdas filhas de pais surdos. Dissertação (Mestrado em Letras) Instituto de Letras e Artes, PUCRS, Porto Alegre. 1994.

. Aquisição fonológica na Língua Brasileira de Sinais: estudo longitudinal de uma criança surda. Tese (Doutorado em Letras), PUCRS, Porto Alegre, 1999.

LEITE, T. A. A segmentação da língua de sinais brasileira (libras): um estudo linguístico descritivo a partir da conversação espontânea entre surdos. Tese (Doutorado), Universidade de São Paulo, São Paulo, 2008.

A identificação de unidades gramaticais na Libras: uma proposta de abordagem baseada no uso. In. Todas as Letras, Porto Alegre, v. 15, p. 62-87, 2013.

MINEIRO, A.; COLAÇO, D. Introdução à fonética e fonologia na LGP e na Língua Portuguesa. Lisboa: Universidade Católica Editora, 2010.

PÊGO, C. F. Sinais não-manuais gramaticais da LSB nos traços morfológicos e lexicais: um estudo do morfema-boca. Dissertação (Mestrado), Universidade de Brasília, Brasília, 2013. 
QUADROS, R. M. de. Aspectos da sintaxe e da aquisição da língua de sinais brasileira. Letras de Hoje, Porto Alegre, v. 110, p. 125-146, 1997.

Libras. São Paulo: Parábola Editorial, 2019.

Língua Brasileira de Sinais I. Material didático do curso de Letras

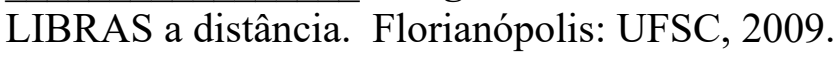

; KARNOPP, L. B. Língua de sinais brasileira: estudos linguísticos.

Porto Alegre: Artmed Editora, 2004.

RIBEIRO, E. S. A constituição sígnica da Libras: uma proposta intersemiótica. In: Estudos Semióticos (USP), v. 6, p. 46-53, 2009.

REILLY, J. How faces Come to serve Grammar: tehe development of nonmanual morphology in American Sign Language. In: SCHICK, B.; MARSCHARK, M.; SPENCER, P. E. (Org.) Advances in the sign language development of deaf children, p. 235 - 312, New York: Oxford University Press, 2006.

; MCINTIRE, M. L.; SEAGO, H. Affective prosody in American Sign Language. In: Sign Language Studies, p.113 -128, 1992.

ROSA, A. S. Entre a visibilidade da tradução da língua de sinais e a invisibilidade da tarefa do intérprete. Petrópolis: Arara Azul, 2010.

SANDLER, W.; LILLO-MARTIN, D. Sign Language and Linguistic Universals. Cambridge University Press, 2006.

SANTOS, R. Correia dos. Estrutura fonológica da língua brasileira de sinais e da língua portuguesa: questões sobre a (in)dependência na estrutura linguística. in Cadernos do CNLF (CiFEFil), v. XVI, p. 1897-1907, 2012.

SILVA, D. S. da. A atuação do intérprete de Libras em uma instituição de ensino superior. Dissertação (Mestrado), Universidade Federal do Ceará, Fortaleza, 2013.

SILVA, L. da. Língua Brasileira de Sinais - Libras. Curitiba: Fael, 2010.

SOUZA e LIMA, V.L. de. Língua de Sinais proposta terminológica para a área de desenho arquitetônico. Tese (Doutorado em Linguística Teórica e Descritiva), Universidade Federal de Minais Gerais, Belo Horizonte, 2014.

SOUZA, D.T. de. Língua Brasileira de Sinais: as dificuldades encontradas por utentes de língua portuguesa na execução da marcação não-manual e sua implicação na mudança de significado. Monografia (Graduação em Letras), Pontifícia Universidade Católica do Rio Grande do Sul, Porto Alegre, 2008.

. Libras: as dificuldades apontadas por ouvintes na execução da marcação

não-manual. FURB: Linguagens-Revista de Letras, Artes e Comunicação, Blumenau, v.2, n.3, p. 279-290, 2009. 
. (Re)visitando as expressões não-manuais em estudos sobre a Libras. Dissertação (Mestrado em Linguística Aplicada), Universidade do Vale do Rio dos Sinos, São Leopoldo, 2014.

. (em elaboração). A constituência prosódica da Língua Brasileira de Sinais (Libras): as expressões não-manuais. Tese (Doutorado em Letras), Universidade Federal do Rio Grande do Sul, Porto Alegre, 2020.

STOKOE, W. C. Sign language structure: an outline of the communication systems of the American deaf. In: Studies in Linguistics: occasional papers. University of Buffalo, NY, p. $3-37,1960$.

A dictionary of American Sign Language on linguistic principles. Silver Spring, Md: Linstok Press, 1976.

TEMÓTEO, J. G. Diversidade linguístico-cultural da língua de sinais do Ceará: um estudo lexicológico das variações da Libras na comunidade de surdos do sítio Caiçara. Dissertação (mestrado), Universidade Federal da Paraíba, João Pessoa, 2008.

XAVIER, A. N. Descrição fonético-fonológica dos sinais da Língua Brasileira de Sinais (Libras). Dissertação (Mestrado), Universidade de São Paulo, São Paulo, 2006.

Variação fonológica na Libras: um estudo da alternância no número de articuladores manuais envolvidos na produção de sinais. In: Anais dos Seminários de teses em andamento, p. $119-145,2011$.

. Análise preliminar de expressões não-manuais lexicais nas libras. In:

Revista Intercâmbio, v. XL, p. 41-66, 2019.

; BARBOSA, P. A. Diferentes pronúncias em uma língua não sonora?

Um estudo da variação na produção de sinais da Libras, D.E.L.T.A, v. 30, n. 2, p. 371-413, 2014. 